\begin{tabular}{c} 
Volume and Issues Obtainable at Center for Sustainability Research and Consultancy \\
Journal of Accounting and Finance in Emerging Economies \\
ISSN: 2519-0318 ISSN (E) 2518-8488 \\
Volume 6: Issue 4 December 2020 \\
CSRE \\
Journal homepage: www.publishing.globalcsrc.org/jafee \\
\hline
\end{tabular}

\title{
Effects of Covid on Co2 Reduction and Climate Change
}

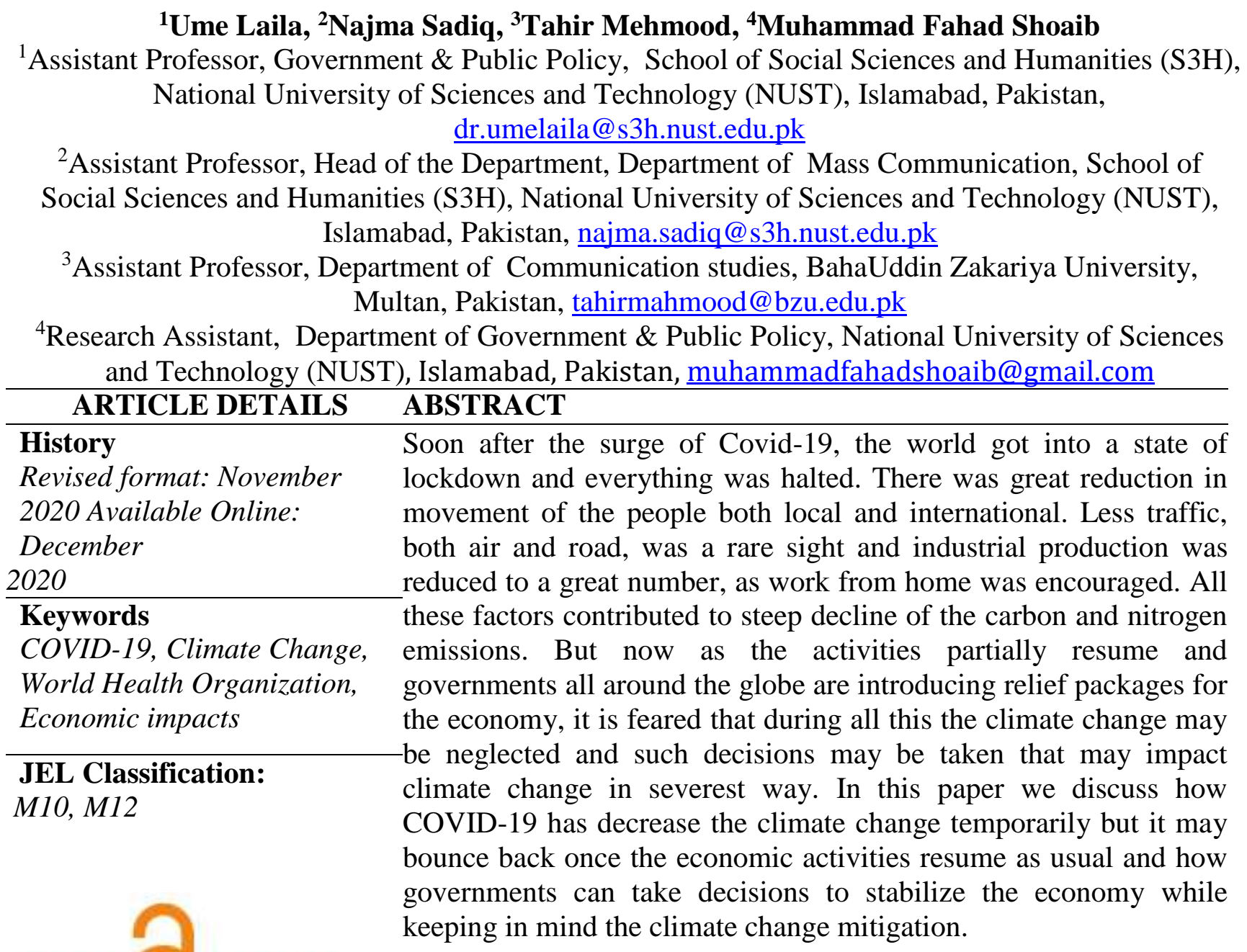

(C) 2020 The authors, under a Creative Commons AttributionNonCommercial 4.0

Corresponding author's email address: dr.umelaila@s3h.nust.edu.pk

Recommended citation: Laila, U., Sadiq, N., Mehmood, T. \& Shoaib, M. F. (2020). Effects of Covid on Co2 Reduction and Climate Change. Journal of Accounting and Finance in Emerging Economies, 6(4), 1015-1020

\section{Introduction}

As cases of novel coronavirus started to spread around the globe at the start of 2020 world health organisations declared COVID-19 a global pandemic on March 11, 2020. (Catrin Sohrabi, 2020) Governments all around the world started to place preventive measures in the form of isolation in homes, locking down the districts, ban on gatherings, closure of schools, offices and workplaces and mandatory home confinements. As these measures were placed in almost all of the countries around the globe and most of the population in the world was confined in homes which led to a drastic decrease in the use of energy and fossil fuels. According to research conducted by Earth system science data, the 
emissions of $\mathrm{CO} 2$ are rising by a factor of $1 \%$ per year over the period of the last 10 years. (Corinne Le Quéré, 2020) Yet according to the international energy agency it is estimated that there has been a 5\% decline in the global CO2 emissions in the first quarter of 2020 when compared to the same period last year. According to another estimate the total $\mathrm{CO} 2$ emission globally reduced by $8.8 \%$ in the first half of 2020 than 2019. (Zhu Liu, 2020).

One of the major reasons for this decrease in $\mathrm{CO} 2$ emission is because of the decrease in industrial activities. Although the consumption side was not much affected but the supply-side was disrupted because of the shutdown of industry around the globe. (R Maria del Rio-Chanona, 2020) Second reason was that due to the lockdown around the world, people were encouraged to work from their homes rather than going to the officers or their workplaces. Public transport was shut down and intrastate and interstate movement was curtailed. Resultantly, decreasing CO2 emission in the atmosphere. This lockdown on one hand helps decrease carbon emission but on the other hand it has created a huge economic depression around the globe which many scholars argue that could be a cause of making climate change more adverse. (Cameron Hepburn, 2020) Economies all around the world faced drastic decline as industries and workforce all around the world were closed and home confined.

As the lockdowns are being lifted, and the economic activities are resuming, the governments are giving a stimulus to stabilize the economy. Resultantly there is going to be a full thrust of industries which can exacerbate the situation of climate. Many G-20 countries have introduced the rescue policies of the economy which cover the fuel intensive industries as well. According to an estimate of the IMF the countries have stepped their economic relief package up to around \$9 Trillion. (Bryn Battersby, 2020).

Climate change should be treated the way we are treating the Corona virus. The impacts of climate change are and will be much graver on human health, economy, ecosystem, society as a whole and on the wellbeing of the planet. there is a need of global intervention in the form of monitoring and control from international agencies to help countries make such economic recovery packages that focus on economy as well as the climate change. These policy designs should mainly focus on clean R\&D and green physical infrastructure which can help reduce the carbon emission and achieve the goals of UNFCCC.

\section{Scope of the study}

Scope of this study mainly comprises the analysis of the the governmental economic recovery packages all around the globe, on the climate change. The report includes how the climate change started to mitigate during the lockdown because of the pandemic and the reduction of the $\mathrm{CO} 2$ in atmosphere in major industrial regions of the world. Following the recommendations that can help government design such policies to ensure the climate change is not affected by the economic packages. As most of the data was taken electronically and no such physical research was conducted due to the lockdown the data may show some discrepancies as the data set was was very large so it was difficult to show the complete range of results of $\mathrm{CO} 2$ emissions. The reposts mainly aims to bring a conclusive evidence that how the COVID-19 economic recovery package may damage the environment and help governments and Intergovernmental Agencies to get the get a comprehensive idea about the situation.

\section{Methodology}

The nature of the research is secondary, and the data is gathered through electronic sources. The data is acquired from different International data houses for climate change monitoring sites and the economic data is acquired from the government and intergovernmental site sources. As the data set is large and the scope of the study is large the data may had some discrepancies and the data set may not be fully able to explain the research question as no first hand information was collected during the research to fit the question. 


\section{Literature Review}

\subsection{Background of Climate Change}

Soon after the start of industrial revolution in the late 19th century scientists started to argue that the emissions of greenhouse gases from the industries could lead to the warming of temperature of the globe. to support this evidence scientist started to produce theories of climate change involving solar variation, volcanism, depletion of ozone layer, depletion of glaciers and so and so forth. As the evidence became more convincing the idea of climate change and global warming gained much attention in the corridor off policy institutions. Governments around the globe set up their own institutions and ministries for the protection and conservation of the climate in their respective countries. Yet to control the change in the climate a global approach was needed, for which international institutions had to intervene to form a global policy for the mitigation and reduction of $\mathrm{CO} 2$ emissions.

The first international climate change conference was organised by the United Nations formerly known as the United Nations Conference on Environment and Development informally known as the Earth summit. Aim of this conference was to stabilize the concentration of greenhouse gases in the atmosphere to prevent the change in climate and rising of the temperatures. In December 1997 treaty known as Kyoto Protocol, an extension of UNFCCC, was adopted by 192 two parties which aimed to reduce the onset of climate change by reducing the global greenhouse gas emissions to a level that would preclude dangerous anthropogenic interference with the climate system. To achieve this, aim the Kyoto Protocol set the target that global warming limited to below 2 degrees Celsius compared to the preindustrial temperature levels. (Depledge, 2000)

Soon it the global community realised, that the Kyoto Protocol was too flattering, and the signatory countries were struggling to find an alternative framework. At the 15th conference of parties in Copenhagen in 2009 more than hundred political leaders got together to negotiate the differences in the matter of climate change and formalized political agreement to set goals for limiting the global temperature increase up to 2 degree Celsius (Framework Convention on, Report of the Conference of the Parties on its sixteenth session, held in Cancun from 29 November to 10 December 2010 , 2011). Conference of parties COP 21 in Paris, the parties adopted Paris agreement. This agreement sets target for each country for the reduction of carbon emissions and introduces the phenomena of carbon credits which each country must follow or must pay the price of the emissions beyond assigned number. (Luca Lo Re, 2019)

\subsection{Reduction During the Pandemic}

As cases of novel coronavirus started to spread around the globe at the start of 2020 world health organisations declared COVID-19 a global pandemic on March 11, 2020. (Catrin Sohrabi, 2020) The virus spread quickly from China to all parts of the world, making its epicentre in Europe and then in the United States of America. Governments all around the world started to place preventive measures in the form of isolation in homes, locking down the districts, ban on gatherings, closure of schools, offices and workplaces and mandatory home confinements. As these measures were placed in almost all of the countries around the globe and most of the population in the world was confined in homes which led to a drastic decrease in the use of energy and fossil fuels.

With all these preventive measures placed, there was a steep decline in emission of carbon dioxide in the atmosphere with respect to the previous decade. According to research conducted by Earth system science data, the emissions of $\mathrm{CO} 2$ are rising by a factor of $1 \%$ per year over the period of the last 10 years. (Corinne Le Quéré, 2020) Yet according to the international energy agency it is estimated that there has been a 5\% decline in the global CO2 emissions in the first quarter of 2020 when compared to the same period last year. According to another estimate the total $\mathrm{CO} 2$ emission globally reduced by 8.8 $\%$ in the first half of 2020 than 2019. (Zhu Liu, 2020) According to European environmental agency NO2 concentration of Nitrogen dioxide reduced to a significant amount many urban centers of Europe. In some cities like Barcelona and Lisbon the reduction was as low as 50\%. (Air pollution goes down as 
Europe takes hard measures to combat coronavirus, 2020).

One of the major reasons for this decrease in $\mathrm{CO} 2$ emission is because of the decrease in industrial activities. Although the consumption side was not much affected but the supply-side was disrupted because of the shutdown of industry around the globe (R Maria del Rio-Chanona, 2020). This resulted in decrease of fossil fuel consumption and less CO2 emission. Second reason was that due to the lockdown around the world, people were encouraged to work from their homes rather than going to the officers or their workplaces. Public transport was shut down and intrastate and interstate movement was curtailed. Resultantly, decreasing CO2 emission in the atmosphere. This not only helped in decreasing the $\mathrm{CO} 2$ emissions but also decreasing the air pollution and increasing the air quality for breathing in numerous cities of the world. Cities which previously had their skylines covered with smoke and dust now saw a clear skyline after an exceptionally long time. (Bourzac, 2020).

\subsection{The Economic Resurge}

A major part of the discussion should be based upon what happens once the economic activities resume all around the world. Economies all around the world faced drastic decline as industries and workforce all around the world were closed and home confined. According to one of the estimates around $81 \%$ of the total labour force of the world was affected by the COVID-19 lockdown. (R. Maria del RioChanona, 2020) This lockdown on one hand helps decrease carbon emission but on the other hand it has created a huge economic depression around the globe which many scholars argue that could be a cause of making climate change more adverse. As the lockdowns are being lifted, and the economic activities are resuming, the governments are giving a stimulus to stabilize the economy. Resultantly there is going to be a full thrust of industries which can exacerbate the situation of climate. (Cameron Hepburn, 2020) Recently President Donald Trump before the completion of his tenure rolled back around 100 environmental rules to boost the economy of the United States. The adverse effect of this roll back is that all the industries are a major contributor in the production of CO2 and NO2. (Gillam, 2020).

Not just the United States but almost every country has this objective to introduce recovery packages in order to stabilize and restore the economy, without keeping in mind the climate change mitigation. Many G-20 countries have introduced the rescue policies of the economy which cover the fuel intensive industries as well, like Russian Express for airlines, (Nikitina, 2020) Australian airline relief and for us airlines development introduced CARES Act. (Cameron Hepburn, 2020) All these and other relief packages mainly target the decreasing deficits of fiscal accounts, caused by the lockdown, restoring life to "business as usual". According to an estimate of the IMF the countries have stepped their economic relief package up to around \$9 Trillion. (Bryn Battersby, 2020) This implies that a sudden surge of CO2 emissions will be there, likely to create an uncertain damage to the global climate. Yet, these decisions may help quick recovery of the economy but these decisions may have a grave impact on the lives of the people in the long run as this fiscal package can be one of the biggest drivers of climate change in the long term.

\section{Recommendations}

One thing that is similar between COVID-19 and climate change is that both need global attention and effort in order to protect the people of this planet. Climate change is also killing people just like the COVID-19 but in a slower manner. Both create market failures and externalities that require international cooperation and unity of the political leadership, to fight against. As more and more research is being conducted overtime on the effects of climate and COVID-19, many scientists have started to argue that the mortality rate due to COVID-19 is higher in those regions of the world where the air quality more degraded as compared to the mortality rate due to COVID-19 of those areas where air quality is better. ( $\mathrm{Wu}, 2020)$

Strictly speaking by keeping in mind the above-mentioned facts, it is time for the governments and policy making institutions to start to focus on climate change. This will not only help in making the 
environment clean but also reduce the fiscal pressure from main sectors like health and can possibly prevent another health crisis like COVID-19 in future. Following are some recommendations which we identified and compiled,

- $\quad$ Design and implement such policies that can benefit the economy and climate simultaneously. This means generating sources of income that are eco-friendly and economically viable. For example, production of hybrid cars and producing electricity using renewable resources helps reduce fossil fuel consumption and decreases the cost of energy production and as well as transportation.

- $\quad$ The economic recovery plans should mainly focus on clean physical infrastructure investment to develop renewable resources that can help start the economic cycle and conserve the environment.

- These bailout packages and recovery plans should focus on more clean research and development of eco-friendly mechanisms of communication and work. Just like me, during the lockdown many people worked from home instead of commuting to their offices. This reduced the great burden of traffic and made the atmosphere cleaner. These policies should encourage people to work from home as much as they can and whenever it is possible for them.

- Government policies should focus on development of public healthcare systems as it will promote the economic cycle as well as the public welfare. Investing money in Public health care can reduce the burden on the people who are economically unable to pay the private health Care fee. This will also help reduce the burden from the existing system.

- The economic policies developed for rural centres should focus on promotion of environmentally friendly agricultural practices and regeneration of the natural ecosystem. Such policies will encourage people to work and earn their livelihood alongside the conservation of the environment.

- These recovery packages should also focus on the development of clean research and development that can help reduce climate change and provide more economically viable solutions to the problems of the future.

The most important point is that these recovery plans should be designed not just according to the needs of the economy but also keeping in mind the situation of climate change. Poorly designed policies can have a grave and long-lasting impact as the whole world is trying to give these recovery packages in order to boost the economy. In order to make an effective policy plan, governments need to collaborate with NGOs locally as well as the international agencies. Not only this but this is why international bodies should also play their part in helping the countries making these recovery policies and making sure that they are aligned with the climate policy of the United Nations Framework Convention on Climate Change.

\section{Conclusion}

Climate change should be treated the way we are treating the Corona virus. The impacts of climate change are and will be much graver on human health, economy, ecosystem, society as a whole and on the wellbeing of the planet. The decrease in $\mathrm{CO} 2$ emissions that we saw during the first two quarters of the year will yield no benefit as it is feared that the economic recovery packages given by the government, to boast the fuel intensive industry, can be life threatening to the planet. The resurgence of the global economy in the form of $\mathrm{V}$ curve can change the dynamics of the climate to such an extreme level where there will be a no chance for any global intervention to make the reversal of climate change possible. So, there is a need of global intervention in the form of monitoring and control from international agencies to help countries make such economic recovery packages that focus on economy as well as the climate change. These policy designs should mainly focus on clean R\&D and green physical infrastructure which can help reduce the carbon emission and achieve the goals of UNFCCC to make the planet a safer place for the generations to come. 


\section{References}

Air pollution goes down as Europe takes hard measures to combat coronavirus. (2020, March 25). Retrieved from European Environmental Agency: https://www.eea.europa.eu/highlights/airpollution-goes-down-as

Bourzac, K. (2020, September 5). COVID-19 lockdowns had strange effects on air pollution across the globe. Retrieved from Chemical \& Engineering News: https://cen.acs.org/environment/atmospheric-chemistry/COVID-19-lockdowns-had-strange-effects-onair-pollution-across-the-globe/98/i37

Bryn Battersby, W. R. (2020, May 20). Tracking the $\$ 9$ Trillion Global Fiscal Support to Fight COVID-19. Retrieved from IMFBlog: https://blogs.imf.org/2020/05/20/tracking-the-9-trillion-globalfiscal-support-to-fight-covid-19/

Cameron Hepburn, B. O. (2020, May 8). Will COVID-19 fiscal recovery packages accelerate or retard progress on climate change? Oxford Review of Economic Policy, 36(Supplement_1), S359-S381. Retrieved from https://academic.oup.com/oxrep/article/36/Supplement_1/S359/5832003?searchresult=1\#207811689

Catrin Sohrabi, Z. A.-J. (2020). World Health Organization declares global emergency: A review of the 2019 novel coronavirus (COVID-19). International Journal of Surgery, Pages 71-76.

Corinne Le Quéré, R. B.-G. (2020, May 19). Temporary reduction in daily global CO2 emissions during the COVID-19 forced confinement. Retrieved from Nature Climate Change: https://www.nature.com/articles/s41558-020-0797-x\#citeas

Depledge, J. (2000, August). TRACING THE ORIGINS OF THE KYOTO PROTOCOL: AN ARTICLE BY ARTICLE TEXTUAL HISTORY. Retrieved from unfccc: http://unfccc.int/resource/docs/tp/tp0200.pdf

Framework Convention on, Report of the Conference of the Parties on its sixteenth session, held in Cancun from 29 November to 10 December 2010 . (2011, March 15). Retrieved from UNFCCC: http://unfccc.int/resource/docs/2010/cop16/eng/07a01.pdf\#page=2

Gillam, C. (2020, October 15). While We Focus on COVID-19, Trump's EPA Is Quietly Killing Us. Retrieved from EcoWatch: https://www.ecowatch.com/trump-epa-rollbacks-covid-2648440328.html

Luca Lo Re, E. A. (2019, July 5). Carbon market negotiations under the Paris Agreement. Retrieved from IEA: https://www.iea.org/commentaries/carbon-market-negotiations-under-the-parisagreement

Nikitina, I. O. (2020, March 24). COVID-19: Russian legal impact. Retrieved from White \& Case: https://www.whitecase.com/publications/alert/covid-19-russian-legal-impact

R Maria del Rio-Chanona, P. M. (2020, August 19). Supply and demand shocks in the COVID19 pandemic: an industry and occupation perspective. Oxford Review of Economic Policy, Volume 36(Issue Supplement_1), $\quad$ S94-S137. $\quad$ Retrieved from https://academic.oup.com/oxrep/article/36/Supplement_1/S94/5899019?searchresult=1

R. Maria del Rio-Chanona, P. M. (2020, April 14). Supply and demand shocks in the COVID-19 pandemic: An industry and occupation perspective. Retrieved from Cornell University: https://arxiv.org/abs/2004.06759

$\mathrm{Wu}, \mathrm{X} . \mathrm{N}$. (2020). Fine particulate matter and COVID-19 mortality in the United States, A national study on long-term exposure to air pollution and COVID-19 mortality in the United States. Retrieved from Harvard University: https://projects.iq.harvard.edu/covid-pm

Zhu Liu, P. C. (2020, October 14). Near-real-time monitoring of global CO2 emissions reveals the effects of the COVID-19 pandemic. Retrieved from Nature Communications: https://www.nature.com/articles/s41467-020-18922-

7\#: :text=We\%20estimate\%20that\%20total\%20global,\%25\%20in\%2020201\%2C23. 